\title{
Dopamine and Opioid Neurotransmission in Behavioral Addictions: A Comparative PET Study in Pathological Gambling and Binge Eating
}

\author{
Joonas Majuri*,1,2,3 Juho Joutsa $^{1,2,3}$, Jarkko Johansson ${ }^{3}$, Valerie Voon ${ }^{4}$, Kati Alakurtti ${ }^{3,5}$, Riitta Parkkola $^{5}$, \\ Tuuli Lahti ${ }^{6}$, Hannu Alho ${ }^{6}$, Jussi Hirvonen ${ }^{3,5}$, Eveliina Arponen ${ }^{3,7}$, Sarita Forsback ${ }^{3,7}$ and Valtteri Kaasinen ${ }^{1,2,3}$ \\ 'Division of Clinical Neurosciences, Turku University Hospital, Turku, Finland; ${ }^{2}$ Department of Neurology, University of Turku, Turku, Finland; ${ }^{3}$ Turku \\ PET Centre, University of Turku, Turku, Finland; ${ }^{4}$ Department of Psychiatry, University of Cambridge, Cambridge, UK; ${ }^{5}$ Department of Radiology, \\ University of Turku and Turku University Hospital, Turku, Finland; 'D Department of Health, Unit of Tobacco, Alcohol and Gambling, National Institute \\ of Health and Welfare, Helsinki, Finland; ${ }^{7}$ Turku PET Centre, Åbo Akademi University, Turku, Finland
}

\begin{abstract}
Although behavioral addictions share many clinical features with drug addictions, they show strikingly large variation in their behavioral phenotypes (such as in uncontrollable gambling or eating). Neurotransmitter function in behavioral addictions is poorly understood, but has important implications in understanding its relationship with substance use disorders and underlying mechanisms of therapeutic efficacy. Here, we compare opioid and dopamine function between two behavioral addiction phenotypes: pathological gambling (PG) and binge eating disorder (BED). Thirty-nine participants (I5 PG, 7 BED, and 17 controls) were scanned with $\left[{ }^{11} \mathrm{C}\right]$ carfentanil and $\left[{ }^{18} \mathrm{~F}\right] \mathrm{fluorodopa}$ positron emission tomography using a high-resolution scanner. Binding potentials relative to non-displaceable binding $\left(\mathrm{BP}_{\mathrm{ND}}\right)$ for [ $\left.{ }^{\mathrm{I}} \mathrm{C}\right]$ carfentanil and influx rate constant $\left(K_{i}\right)$ values for $\left[{ }^{18} \mathrm{~F}\right]$ fluorodopa were analyzed with region-of-interest and whole-brain voxel-by-voxel analyses. BED subjects showed widespread reductions in $\left[{ }^{1} \mathrm{C}\right]$ carfentanil $\mathrm{BP} \mathrm{ND}_{\mathrm{N}}$ in multiple subcortical and cortical brain regions and in striatal $\left[{ }^{18} \mathrm{~F}\right]$ fluorodopa $K_{i}$ compared with controls. In PG patients, $\left[{ }^{11} \mathrm{C}\right]$ carfentanil $\mathrm{BP} \mathrm{ND}_{\mathrm{N}}$ was reduced in the anterior cingulate with no differences in $\left[{ }^{18} \mathrm{~F}\right]$ fluorodopa $K_{i}$ compared with controls. In the nucleus accumbens, a key region involved in reward processing, $\left[{ }^{1} \mathrm{C}\right]$ Carfentanil BP ${ }_{N D}$ was 30-34\% lower and $\left[{ }^{18} \mathrm{~F}\right]$ fluorodopa $K_{i}$ was $20 \%$ lower in BED compared with PG and controls $(p<0.002)$. BED and PG are thus dissociable as a function of dopaminergic and opioidergic neurotransmission. Compared with PG, BED patients show widespread losses of mu-opioid receptor availability together with presynaptic dopaminergic defects. These findings highlight the heterogeneity underlying the subtypes of addiction and indicate differential mechanisms in the expression of pathological behaviors and responses to treatment.

Neuropsychopharmacology (2017) 42, I |69-I I77; doi:I0.I038/npp.2016.265; published online I4 December 2016
\end{abstract}

\section{INTRODUCTION}

Behavioral addictions refer to a group of heterogeneous conditions characterized by the compulsive pursuit of rewards through repetitive behavioral patterns (Robbins and Clark, 2015). What constitutes a behavioral addiction and how they fundamentally compare with substance use disorders remain to be fully defined. Further, why specific disorders are treatable with a specific drug or expressed in certain behaviors remains elusive. Currently, only gambling disorder is classified as a behavioral addiction in the Diagnostic and Statistical Manual of Mental Disorders, Version 5 (DSM-5) with internet gaming disorder classified

\footnotetext{
*Correspondence: Dr J Majuri, Turku PET Centre, University of Turku, POB 52, Turku 20521, Finland, Tel: +358-2-3130000, Fax: +358-2-2318191, E-mail: joeema@utu.fi

Received 7 August 2016; revised 12 November 2016; accepted 16 November 2016; accepted article preview online 24 November 2016
}

in Section III as a disorder requiring more study. A number of other phenotypically distinct behaviors have overlapping characteristics, including binge eating disorder (BED), compulsive sexual behaviors, and compulsive shopping (Yau and Potenza, 2015). Pathological gambling (PG) has been viewed as a prototype of a behavioral addiction, with a prevalence of $1-3 \%$. BED is the most frequent of eating disorders (Kessler et al, 2013) and is characterized by the rapid intake of large amounts of food in discrete periods of time and the lack of control over eating behaviors. The phenomenology of PG and BED share many features with substance addictions (Grant et al, 2010b) and mood disorders. Earlier studies have shown that depression symptoms are common in both BED and PG (with possible shared genetic factors), and antidepressants have decreased binge-eating frequency (Brownley et al, 2016; Potenza et al, 2005). Further, it has been suggested that a modification of developmental model for major depression could provide a foundation for the development of a comprehensive model on pathological gambling (Blanco et al, 2015). 
Understanding the underlying neurobiological substrates can help in a neurobiologically driven conceptualization of these disorders and is critical for future efforts in drug development.

Substance use disorders are commonly associated with reduced striatal post-synaptic D2 receptor availability and blunted dopamine responses to pharmacological challenge, such as (met)amphetamine (Volkow et al, 2014). In contrast, converging studies in PG have not shown differences in postsynaptic striatal dopamine D2 receptor availability compared with healthy controls (Boileau et al, 2013; Clark et al, 2012; Joutsa et al, 2012; Linnet et al, 2012). Furthermore, dopaminergic responses to gambling or amphetamine challenge appear to be enhanced in $\mathrm{PG}$, in contrast to substance use disorders (Boileau et al, 2014; Joutsa et al, 2012). Similarly, BED patients have shown no alterations in baseline D2 receptor availability with increased striatal dopamine responses to food stimuli (Wang et al, 2011). Studies of presynaptic dopamine function in substance use disorders have shown mixed results (Bloomfield et al, 2014; Kienast et al, 2013; Wu et al, 1997). Presynaptic dopamine function in PG or BED has not yet been reported. With respect to mu-opioid receptor availability, PG patients have not shown baseline differences but have shown decreased opioid release to amphetamine challenge (Mick et al, 2015). No studies of mu-opioid receptor availability in $\mathrm{BED}$ have been reported. Thus, studies of in vivo neurotransmitter function in PG and BED are in their infancy.

Understanding neurotransmitter function in behavioral addictions is critical for the conceptualization of these behaviors and to understand the mechanisms underlying therapeutic efficacy. Lisdexamfetamine, a prodrug of dextroamphetamine, is the first and only drug approved by the Food and Drug Administration for the treatment of BED (McElroy et al, 2015). This drug increases synaptic dopamine by blocking dopamine reuptake transporters. Hence, understanding presynaptic dopamine function in BED is highly relevant. Rodent studies suggest that the opioid system is implicated in hedonic processing, incentive motivation and consummatory aspects relevant particularly to binge eating (for a review, see Giuliano and Cottone, 2015) and other behavioral and substance use disorders. Opioid antagonists have demonstrated efficacy in alcohol use disorders (Rosner et al, 2010). Naltrexone, a mu-opioid antagonist, has also shown efficacy in some but not all randomized controlled trials for PG (Grant et al, 2008; Kim et al, 2001; Kovanen et al, 2016; Toneatto et al, 2009). The efficacy of nalmefene in PG is also mixed (Grant et al, 2010a; Grant et al, 2006). Two novel opioid antagonists selective for the mu-opioid receptor, ALKS 33 (McElroy et al, 2013) and GSK1521498 (Ziauddeen et al, 2013), have not shown efficacy in binge eating behaviors or weight, although the latter demonstrated effects on hedonic and motivational responses (Cambridge et al, 2013; Ziauddeen et al, 2013). This mixed picture highlights the necessity of understanding the underlying neurotransmitter profile to help guide therapeutic drug efficacy.

Here, we investigated mu-opioid receptor and dopamine neurotransmission using high-resolution $\left[{ }^{11} \mathrm{C}\right]$ carfentanil and $\left[{ }^{18} \mathrm{~F}\right]$ fluorodopa brain PET to directly compare two phenotypically different behavioral addictions, PG and BED. We hypothesized that similar to substance use disorders, both PG and BED would show decreased presynaptic dopamine function and increased mu-opioid receptor binding.

\section{MATERIALS AND METHODS}

\section{Subjects}

Sixty-seven subjects were screened for the study using clinical interviews, basic blood laboratory tests, and urine drug screens. Thirteen subjects were excluded due to scheduling problems, four due to unmet diagnostic criteria for PG or BED, three due to alcohol abuse, two due to DSM IV axis I psychiatric disorder, and six due to other reasons. Thirty-nine subjects were included (17 healthy controls (HC), 15 PG, and 7 BED) (Table 1). Fulfilling the DSM-IV diagnostic criteria of BED or PG was considered as inclusion criteria for the corresponding groups (Table 2), and the

Table I Main Demographic Characteristics of the Studied Sample

\begin{tabular}{|c|c|c|c|c|}
\hline & HC & PG & BED & P-value $^{\mathrm{a}}$ \\
\hline n & 17 & 15 & 7 & \\
\hline Age (years) & $43.3(11.1)$ & $42.6(11.8)$ & $49.4(5.1)$ & 0.35 \\
\hline $\operatorname{Sex}(m / f)$ & $8 / 9$ & $8 / 7$ & $0 / 7$ & 0.048 \\
\hline BMI $\left(\mathrm{kg} / \mathrm{m}^{2}\right)$ & $24.8(2.1)$ & $25.4(3.6)$ & $30.9(6.6)$ & 0.003 \\
\hline Smoking $(y / n)$ & $7 / 10$ & ||$/ 4$ & $2 / 5$ & 0.08 \\
\hline $\mathrm{BDI}$ & $2.8(3.1)$ & | $4.4(7.8)$ & $15.4(9.6)$ & $<0.0001$ \\
\hline Injected dose of $\left[{ }^{\prime \prime} \mathrm{C}\right]$ carfentanil (MBq) & $495(17)$ & $483(49)$ & $504(13)$ & 0.35 \\
\hline Injected mass of $\left[{ }^{1} \mathrm{I} C\right]$ carfentanil $(\mu \mathrm{g})$ & $0.428(0.307)$ & $0.569(0.542)$ & $0.422(0.197)$ & 0.56 \\
\hline Injected dose of $\left[{ }^{18} \mathrm{~F}\right]$ fluorodopa $(\mathrm{MBq})$ & $228(4)$ & $229(12)$ & $225(6)$ & 0.67 \\
\hline Injected mass of $\left[{ }^{18} \mathrm{~F}\right]$ fluorodopa $(\mu \mathrm{g})$ & $9.30(3.31)$ & | $1.28(3.59)$ & $10.54(5.88)$ & 0.40 \\
\hline AUDIT & $5.4(3.3)$ & $5.9(4.0)$ & $3.3(1.1)$ & 0.23 \\
\hline
\end{tabular}

Abbreviations: AUDIT, Alcohol Use Disorders Identification Test; BDI, Beck Depression Inventory; BMI, body mass index.

Values are means (SD) or $n$.

aOne-way ANOVA or $\chi^{2}$ test.

Neuropsychopharmacology 
Table 2 Differences Between Studied Groups in Gambling and Eating Behavior

\begin{tabular}{|c|c|c|c|c|c|}
\hline \multirow[t]{2}{*}{ Behavior } & Item & \multirow{2}{*}{$\frac{\text { Control }}{17}$} & \multirow{2}{*}{$\frac{P G}{15}$} & \multirow{2}{*}{$\frac{\text { BED }}{7}$} & \multirow[t]{2}{*}{$P$-value ${ }^{a}$} \\
\hline & $N$ & & & & \\
\hline \multirow{3}{*}{ Gambling } & SOGS & $0.1(0.3)$ & | $3.3(2.3)$ & $0.4(0.5)$ & $<0.000$ I \\
\hline & Duration of problem gambling (years) & n.a. & I I.6 (7.3) & n.a. & $<0.000$ । \\
\hline & Gambling debt $(€)$ & $0(0)$ & I8000 (I5600) & $0(0)$ & $<0.000$ । \\
\hline \multirow[t]{4}{*}{ Eating } & Binge Eating Scale & $2.1(2.1)$ & $4.4(4.4)$ & $30.9(4.6)$ & $<0.000$ I \\
\hline & Yale food addiction scale & $5.4(3.4)$ & $9.1(9.5)$ & $42.3(6.5)$ & $<0.0001$ \\
\hline & DEBQ emotional & $20.5(5.0)$ & $21.2(8.7)$ & $50.0(8.3)$ & $<0.000$ । \\
\hline & DEBQ external & $23.7(5.3)$ & $26.1(7.3)$ & $37.5(6.3)$ & $<0.000$ । \\
\hline
\end{tabular}

Abbreviations: DEBQ, The Dutch Eating Behavior Questionnaire; PG DSM-IV, DSM-IV diagnostic criteria for pathological gambling; SOGS, South Oaks Gambling Screen; n.a., not applicable.

Missing questionnaire data for one PG patient.

${ }^{a}$ One-way ANOVA.

diagnoses were confirmed with a structured clinical interview. None of the subjects were using medications known to have effects on the opioid or dopamine system. One PG patient was using an SSRI medication citalopram for mild anxiety symptoms. The study protocol was approved by the local ethics committee, and written informed consent was obtained from each participant. The study was conducted according to the principles of the Declaration of Helsinki.

The subjects were instructed to refrain from cigarette smoking $8 \mathrm{~h}$ prior to scanning, from drinking coffee or tea $12 \mathrm{~h}$ prior to scanning, and from drinking alcohol $48 \mathrm{~h}$ prior to scanning. The subjects were allowed to eat a normal breakfast prior to the PET scans. A standard hospital lunch was served between scans. To minimize the possible effects of arousal on tracer binding (Li and van den Pol, 2008), the subjects were not allowed to sleep in the scanner during $\left[{ }^{11} \mathrm{C}\right]$ carfentanil imaging. One $\mathrm{HC}$ was not available for $\left[{ }^{11} \mathrm{C}\right]$ carfentanil analysis due to scanner malfunction, and three subjects (1 HC and $2 \mathrm{PG}$ ) were not available for $\left[{ }^{18} \mathrm{~F}\right]$ fluorodopa analysis.

All included subjects underwent brain MRI with a PETMRI scanner Philips Ingenuity (Philips Healthcare, Cleveland, $\mathrm{OH}, \mathrm{USA}$ ). Anatomical reference images were acquired using both a 34-channel receiving head coil and a sagittal 3DT1-weighted TFE sense pulse sequence (TR $8.1 \mathrm{~ms}$, TE $3.7 \mathrm{~ms}$, flip angle $7^{\circ}$, matrix $256 \times 256,176$ slices) with an isotropic voxel.

\section{Radiochemistry and PET Scanning}

Radioligands were produced according to EU GMP regulations at the Turku PET Centre, as previously described (Forsback et al, 2009; Hirvonen et al, 2009). [ $\left.{ }^{18} \mathrm{~F}\right]$ FDOPA was synthetized via electrophilic radiofluorination. $\left[{ }^{11} \mathrm{C}\right]$ Carfentanil was synthesized via ${ }^{11} \mathrm{C}$-methylation of desmethyl carfentanil (sodium salt) with $\left[{ }^{11} \mathrm{C}\right]$ methyl triflate prepared from cyclotron-produced $\left[{ }^{11} \mathrm{C}\right] \mathrm{methane}$.
Radiochemical purity exceeded $95 \%$ in all production runs, and the specific activity was more than $5 \mathrm{GBq} / \mu \mathrm{mol}$ for $\left[{ }^{18} \mathrm{~F}\right]$ FDOPA and $590 \mathrm{GBq} / \mu \mathrm{mol}$ (SD 290) for $\left[{ }^{11} \mathrm{C}\right]$ carfentanil at the time of injection.

PET scanning for each participant was performed during the same day at fixed times $\left(\left[{ }^{11} \mathrm{C}\right]\right.$ carfentanil scan at $0900-$ 1000 hours, $\left[{ }^{18} \mathrm{~F}\right]$ fluorodopa scan at $1430-1530$ hours). For four subjects (one PG, one BE, and two $\mathrm{HC}$ ), the PET scans were performed on separate days. PET scanning was performed with a dedicated brain 3D HRRT (High Resolution Research Tool; Siemens Medical Solutions, Knoxville, $\mathrm{TN}$, USA) PET scanner with nearly isotropic $2.5 \mathrm{~mm}$ intrinsic spatial resolution (de Jong et al, 2007). The camera was used in $3 \mathrm{D}$ mode with scatter correction. The total scanning time was $51 \mathrm{~min}$ with $\left[{ }^{11} \mathrm{C}\right]$ carfentanil and $90 \mathrm{~min}$ with $\left[{ }^{18} \mathrm{~F}\right]$ fluorodopa. The $\left[{ }^{11} \mathrm{C}\right]$ carfentanil scans consisted of 13 frames, and the $\left[{ }^{18} \mathrm{~F}\right]$ fluorodopa scans were divided into 22 frames. The average doses were 492 (SD 33) $\mathrm{MBq}$ for $\left[{ }^{11} \mathrm{C}\right]$ carfentanil and 228 (SD 8) $\mathrm{MBq}$ for $\left[{ }^{18} \mathrm{~F}\right]$ fluorodopa. A transmission scan was performed prior to each dynamic scanning for attenuation corrections with a ${ }^{137} \mathrm{Cs}$ rotating point source. An individually shaped thermoplastic mask was used with each subject to minimize head movement, and head movements were recorded using a stereotaxic infrared camera (Polaris Vicra, Northern Digital, Waterloo, Canada) during scanning. Three PG patients and one BED patient had a Velcro strap instead of a thermoplastic mask during $\left[{ }^{18} \mathrm{~F}\right]$ fluorodopa scanning.

\section{Preprocessing and Analysis}

Realignment and coregistration steps were performed with SPM8 software running on MatLab R2012a (MathWorks, Natick, MA, USA). First, dynamic PET images were realigned frame-to-frame to correct head movement during the scanning. Individual $\mathrm{T} 1$-weighted $\mathrm{MR}$ images were coregistered to the summed image of the realigned frames 
and resliced to $1.5 \times 1.5 \times 1.5 \mathrm{~mm}$ voxel size. There were three subjects who showed $>2 \mathrm{~mm}$ intra-frame head movement in more than one frame during scanning according to infrared camera data. For these three subjects and five scans, individual reconstructions were made to compensate for intraframe motion. An in-house method corresponding to that described by Keller et al (2012) was employed in motion correction (MC) reconstruction. Shortly, PET list mode data were first subframed according to Vicra-based external motion data using a maximum amplitude of $2.5 \mathrm{~mm}$ as a threshold. Second, all subframes were reconstructed without attenuation correction, and registering transformations to a reference frame were estimated using Automated Image Registration (AIR) software (Woods et al, 1998); third, inverse transformations were employed to register attenuation correction to each subframe and final reconstructions were made with all corrections. Finally, the subframes were registered and combined to form the desired framing.

Individual parametric images were normalized to Montreal Neurological Institute (MNI) standard space and smoothed with a Gaussian kernel of $8 \mathrm{~mm}$ at full-width and half-maximum. Complementary with voxel-by-voxel analyses, tracer kinetics were quantified from the anatomical regions of interest (ROIs). ROIs were determined using FreeSurfer software (version 5.3.0, http://surfer.nmr.mgh. harvard.edu/) using T1-weighted MR images, as described earlier (Alakurtti et al, 2015; Desikan et al, 2006; Fischl et al, 2002). ROIs selected for $\left[{ }^{11} \mathrm{C}\right]$ carfentanil analyses included the putamen, nucleus caudatus, nucleus accumbens, globus pallidus, thalamus, hippocampus, amygdale, and cortical gray matter regions (for a complete list, see Supplementary Table S1), whereas the ROIs included in $\left[{ }^{18} \mathrm{~F}\right]$ fluorodopa consisted only of the subcortical regions putamen, nucleus caudatus, nucleus accumbens, globus pallidus, thalamus, hippocampus, and amygdala. $\left[{ }^{11} \mathrm{C}\right]$ carfentanil-binding potentials (estimates of specific binding relative to nondisplaceable binding or $\mathrm{BP}_{\mathrm{ND}}$ ) were calculated using a simplified reference tissue model and $\left[{ }^{18} \mathrm{~F}\right]$ fluorodopa influx rate constant $K_{\mathrm{i}}$ values using a Patlak plot, both with the occipital cortex as a reference region (Gunn et al, 1997; Patlak and Blasberg, 1985).

\section{Statistics}

Statistical analyses were performed using SPSS (IBM SPSS Statistics, version 22, Armonk, NY, USA). Group differences in demographic data, questionnaire data, and ROI data were investigated using an ANOVA model (three groups) or $\chi^{2}$ tests for categorical variables. Within-group correlations between tracer kinetics and demographical/questionnaire data were tested using Spearman's rank order test. In the ROI ANOVA analysis, $p<0.01$ was considered statistically significant to take into account the effect of multiple comparisons. Bonferroni correction was applied to post hoc tests. Analogous voxel-based analyses were performed using a general linear model implemented in SPM8. In SPM, cluster-level family-wise error (FWE)-corrected $p$-values less than 0.05 were considered significant.

\section{RESULTS}

Patients with BED had lower $\left[{ }^{11} \mathrm{C}\right]$ carfentanil $\mathrm{BP}_{\mathrm{ND}}$ than healthy controls and $\mathrm{PG}$ patients in several brain regions, including the thalamus, the nucleus accumbens, the hippocampus, the posterior cingulate gyrus, the isthmus of the posterior cingulate gyrus, the parahippocampal gyrus, the frontal pole, the pars orbitalis of the ventrolateral prefrontal cortex, the lateral orbitofrontal cortex, and the ventrolateral prefrontal cortex (Table 3, Figure 1 and Supplementary Table S1) in the ROI analysis. The largest decreases in BED

Table 3 Group-Differences in [ ' $\mathrm{C}]$ Carfentanil BP $\mathrm{ND}$ and $\left[{ }^{18} \mathrm{~F}\right.$ Fluorodopa $K_{i}$ Values (ROI Analysis)

\begin{tabular}{|c|c|c|c|c|c|c|c|c|c|}
\hline \multirow[t]{2}{*}{ Tracer } & \multirow[t]{2}{*}{ Region } & \multirow[t]{2}{*}{ HC } & \multirow[t]{2}{*}{ PG } & \multirow[t]{2}{*}{ BED } & \multirow{2}{*}{$\begin{array}{l}\text { F-value } \\
\text { One-way } \\
\text { ANOVA }\end{array}$} & \multirow{2}{*}{$\begin{array}{l}\text { p-value } \\
\text { One-way } \\
\text { ANOVA }\end{array}$} & \multicolumn{3}{|c|}{ post hoc $p$-values ${ }^{a}$} \\
\hline & & & & & & & C vs PG & C vs BED & PG vs BED \\
\hline \multirow[t]{6}{*}{$\begin{array}{l}{\left[{ }^{\prime \prime} \mathrm{C}\right]} \\
\text { carfentanil }\end{array}$} & $\begin{array}{l}\text { Isthmus of PCC } \\
\text { Nucleus accumbens }\end{array}$ & $\begin{array}{c}0.469(0.092) \\
2.27(0.26)\end{array}$ & $\begin{array}{c}0.416(0.113) \\
2.12(0.33)\end{array}$ & $\begin{array}{c}0.191(0.089) \\
1.49(0.29)\end{array}$ & $\begin{array}{l}18.9 \\
17.5\end{array}$ & $\begin{array}{l}<0.0001 \\
<0.0001\end{array}$ & $\begin{array}{l}0.468 \\
0.502\end{array}$ & $\begin{array}{l}<0.0001 \\
<0.0001\end{array}$ & $\begin{array}{l}<0.0001 \\
<0.0001\end{array}$ \\
\hline & Frontal pole & $0.765(0.206)$ & $0.803(0.244)$ & $0.350(0.177)$ & 11.4 & $<0.0001$ & 1.000 & 0.001 & $<0.0001$ \\
\hline & $\begin{array}{l}\text { Parahippocampal } \\
\text { gyrus }\end{array}$ & $0.296(0.086)$ & $0.259(0.086)$ & $0.142(0.100)$ & 7.5 & 0.002 & 0.755 & 0.001 & 0.019 \\
\hline & PCC & $0.874(0.166)$ & $0.856(0.144)$ & $0.630(0.159)$ & 6.5 & 0.004 & 1.000 & 0.005 & 0.010 \\
\hline & Thalamus & $1.41(0.18)$ & $1.33(0.25)$ & $1.07(0.17)$ & 6.5 & 0.004 & 0.981 & 0.003 & 0.027 \\
\hline & Hippocampus & $0.211(0.089)$ & $0.218(0.107)$ & $0.0736(0.108)$ & 5.7 & 0.007 & 1.000 & 0.013 & 0.010 \\
\hline
\end{tabular}

Abbreviations: LOF, lateral orbitofrontal cortex; PCC, posterior cingulate gyrus; VPC, ventrolateral prefrontal cortex.

VPC is formed by fusing primary ROls pars opercularis, pars orbitalis, and pars triangularis.

Regions with a significance level of $p<0.01$ in ANOVA are presented. Other regions-of-interest are presented in Supplementary Table SI.

aBonferroni corrected. 
a

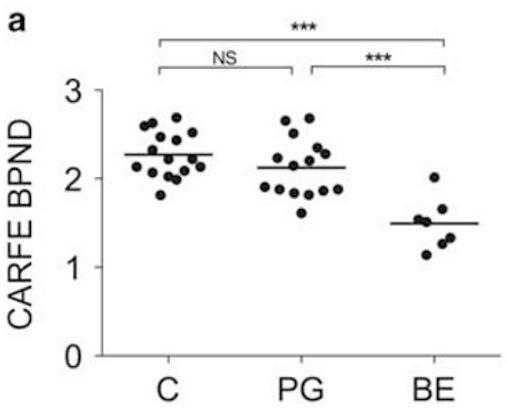

C

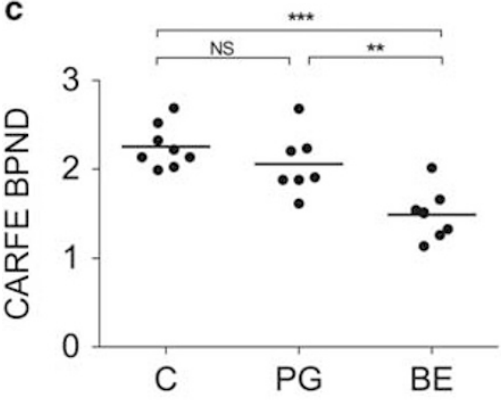

e

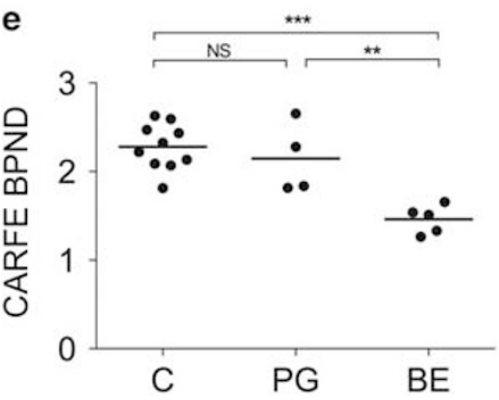

b

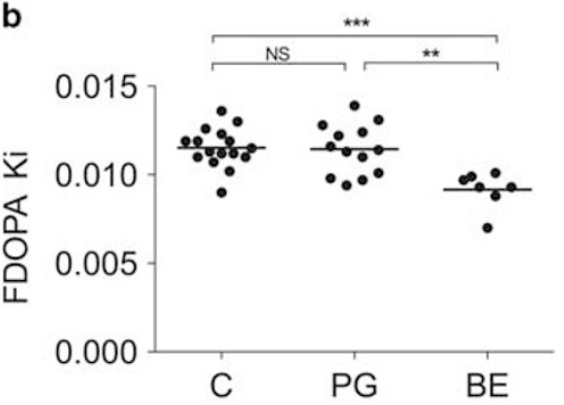

d

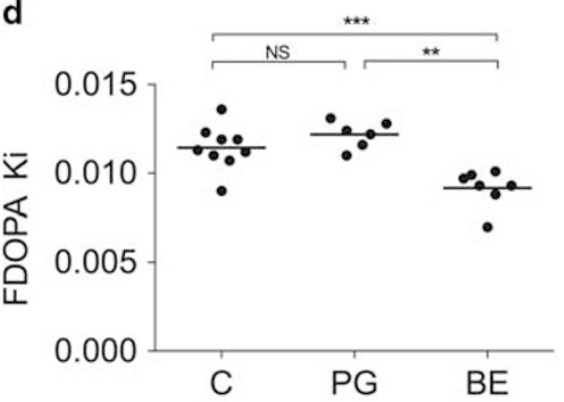

f

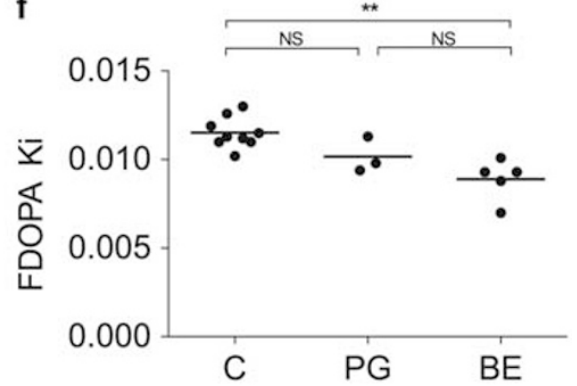

Figure I Nucleus accumbens $\left[{ }^{1} \mathrm{C}\right]$ carfentanil-binding potentials $\left(\mathrm{BP}_{\mathrm{ND}}\right)$ and $\left[{ }^{18} \mathrm{~F}\right]$ fluorodopa $K_{\mathrm{i}}$ values in healthy controls $(\mathrm{C})$, pathological gamblers (PG), and binge eaters (BE). Statistical significance denotes Bonferroni-corrected post hoc tests after one-way ANOVA. **** $<0.00 \mathrm{I}$, *** $<0.0 \mathrm{I}$, $\mathrm{NS}=$ nonsignificant. Means of the left and right hemisphere values are presented. (a) $\left.{ }^{1}{ }^{\prime} \mathrm{C}\right]$ carfentanil, all subjects. (b) $\left[{ }^{18} \mathrm{~F}\right]$ fluorodopa, all subjects. (c) $\left[{ }^{1} \mathrm{C}\right]$ carfentanil, women only. (d) $\left[^{18} \mathrm{~F}\right]$ fluorodopa, women only. (e) $\left[{ }^{1 /} \mathrm{C}\right]$ carfentanil, non-smokers only. (f) $\left[{ }^{18} \mathrm{~F}\right]$ fluorodopa, non-smokers only.

compared with PG patients were observed in the hippocampus $(66 \%$ lower in $\mathrm{BED}, p=0.010)$, the frontal pole $(56 \%$ lower in $\mathrm{BED}, p<0.0001)$, and the isthmus of the posterior cingulate gyrus (54\% lower in BED, $p<0.0001)$. In the nucleus accumbens, BED patients had $30 \%$ lower $\left[{ }^{11} \mathrm{C}\right]$ carfentanil binding than PG patients $(p<0.0001)$ (Table 3$)$. With $\left[{ }^{18} \mathrm{~F}\right]$ fluorodopa, patients with BED had lower $K_{\mathrm{i}}$ than healthy controls and PG patients in the nucleus accumbens (20\% with $p<0.001$ and $20 \%$ with $p=0.001$, respectively) (Table 3, Figure 1 and Supplementary Table S1). All other group comparisons were nonsignificant.

The results remained the same when males (Figures $1 \mathrm{c}$ and $\mathrm{d}$ ) and smokers (Figures le and $\mathrm{f}$ ) were excluded from the analysis. Furthermore, including BMI, age or AUDIT score as covariates in ANOVA did not change the primary results.

Correlation analyses with ROI values were performed with $\left[{ }^{18} \mathrm{~F}\right]$ fluorodopa $K_{\mathrm{i}}$ for the nucleus accumbens and $\left[{ }^{11} \mathrm{C}\right]$ carfentanil $\mathrm{BP}_{\mathrm{ND}}$ for the regions that showed the largest group differences (the isthmus of the cingulate, the nucleus accumbens, the frontal pole, and the pars orbitalis of the ventrolateral prefrontal cortex). In BED patients, no significant correlations were observed with symptom severity scores, including the DEBQ, BES, and Yale food addiction scale score. In PG patients, tracer binding did not correlate with gambling-related severity ratings such as gambling hours per week or SOGS. Correlations were similarly nonsignificant using both ROI and SPM-based analyses.

An independent voxel-based whole-brain analysis using SPM confirmed the ROI-based results by showing a large cluster of lower $\left[{ }^{11} \mathrm{C}\right]$ carfentanil binding in $\mathrm{BED}$ patients compared with controls, particularly in the posterior cingulate gyrus, the thalamus, the anterior cingulate gyrus and the midbrain (Figure 2a). Differences in $\left[{ }^{11} \mathrm{C}\right]$ carfentanil $\mathrm{BP}_{\mathrm{ND}}$ were also observed between $\mathrm{BED}$ and $\mathrm{PG}$ in the frontal cortex (lower in $\mathrm{BED}$, cluster size $59.9 \mathrm{~cm}^{3}$, peak voxel at $\left.-9,63,33 \mathrm{~mm}, t_{\max }=6.18, p_{\mathrm{FWE}}<0.001\right)$ and between PG patients and controls bilaterally in the anterior cingulate cortex and posterior cingulate cortex (lower in PG; Figure 2a). With $\left[{ }^{18} \mathrm{~F}\right]$ fluorodopa, SPM analysis confirmed a lower uptake in BED compared with controls in the nucleus accumbens with the cluster extending to the caudate and putamen (Figure $2 \mathrm{~b}$ ). No significant $K_{\mathrm{i}}$ differences were detected with SPM in the comparisons between the PG and controls or between PG and BED. 

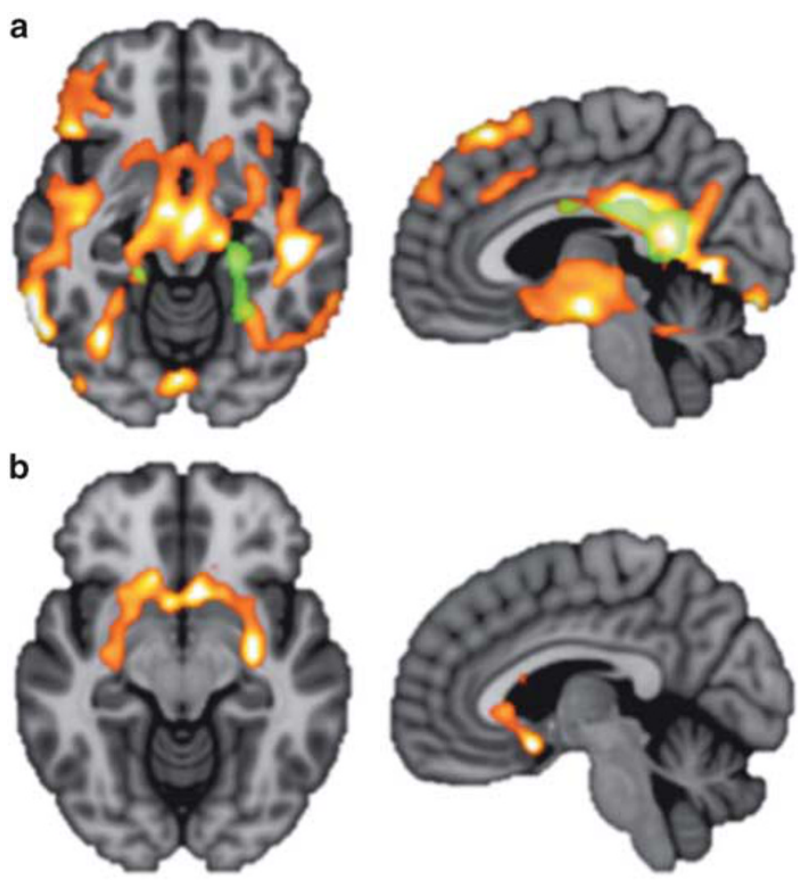

2 4
2

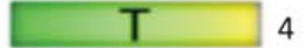

Figure 2 Between-group differences in [ [ $C$ Carfentanil-binding potentials $\left(\mathrm{BP}_{\mathrm{ND}}\right)$ and $\left[{ }^{18} \mathrm{~F}\right.$ fluorodopa $K_{\mathrm{i}}$ values. Significant clusters from the level of the nucleus accumbens are shown on the left. On the right are significant clusters from the level of the left cingulate cortex. The red/yellow-colored clusters illustrate the areas where binge eating disorder (BED) patients had lower tracer binding compared with controls, whereas the green-colored clusters show the areas where tracer binding was lower within pathological gambling (PG) patients compared with controls. (a) $\left[{ }^{11} \mathrm{C}\right]$ carfentanil: $\mathrm{BED}$ (cluster size $248.8 \mathrm{~cm}^{3}$, peak voxel at $-66,-51,-6 \mathrm{~mm}, t_{\max }=6.15$, PFWE $<0.00$ I); PG (cluster size $45.6 \mathrm{~cm}^{3}$, peak voxel at $20-24,34 \mathrm{~mm}$, $\left.t_{\max }=6.04, p_{\mathrm{FWE}}=0.00 \mathrm{I}\right) .(\mathrm{b})\left[{ }^{18} \mathrm{~F}\right]$ fluorodopa: BED (cluster size $16.5 \mathrm{~cm}^{3}$, peak voxel at $-6,1 \mathrm{I},-12 \mathrm{~mm}, t_{\max }=5.16$, P FWE $_{\mathrm{F}}<0.00 \mathrm{I}$ ).

\section{DISCUSSION}

We show that two phenotypically different behavioral patterns, PG and BED, are dissociable as a function of brain opioid and dopamine neurotransmission. BED is characterized by a widespread reduction in mu-opioid receptor availability and striatal dopamine synthesis capacity, whereas PG was only associated with a reduction in mu-opioid receptor availability in the cingulate cortex. These findings have important implications in the conceptualization of disorders of addiction and in possible mechanistic and therapeutic efficacy.

\section{Mu-Opioid Receptor}

Contrary to our hypotheses, the reduced mu-opioid receptor availability, particularly in BED and to a lesser extent in PG, stand in marked contrast to observations in substance use disorders. Elevated mu-opioid receptor availability is observed in cocaine (Zubieta et al, 1996) and alcohol (Heinz et al, 2005) dependence in early abstinence and is associated with craving, severity and predicted relapse and remains stable in early to mid-abstinence. These findings may reflect either differences in the regulation of the mu-opioid receptor

or endogenous opioid release as a function of drugs or exposure to natural rewards or pathological behaviors; alternatively, they may reflect predisposing traits.

Morbid obesity has been associated with low mu-opioid receptor availability, and bariatric surgery appears to normalize low mu-opioid receptor availability despite the patients being overweight after surgery (Karlsson et al, 2015). This particular study suggests that an alteration in opioid function may be more likely to be associated with pathological eating behavior than with body mass. Here, we focus on pathological binge eating behaviors in subjects with, on average, slightly to moderately elevated BMI (mean 30.9 (SD 6.6) $\mathrm{kg} / \mathrm{m}^{2}$; range 22.8-42.1) and show that BMI does not influence $\left[{ }^{11} \mathrm{C}\right]$ carfentanil binding. Further studies are required to explore the relationship between mu-opioid receptor availability and chronic overeating compared with binge eating specifically.

Our findings are consistent with a recent study in PG, demonstrating a blunting of amphetamine-induced changes in mu-opioid receptor availability but without any differences in baseline receptor availability (Mick et al, 2015). The present voxel-based results suggest reductions in mu-opioid receptor availability in the cingulate cortex in PG; however, this finding was not confirmed in our ROI analysis, which utilized predefined anatomical ROIs. The finding of decreased cingulate mu-opioid receptor availability should therefore be considered preliminary and warrants replication. In addition, $\left[{ }^{11} \mathrm{C}\right]$ carfentanil $\mathrm{BP}_{\mathrm{ND}}$ values of our healthy controls were somewhat lower compared with some earlier PET studies (Mick et al, 2015; Karlsson et al, 2015; Hirvonen et al, 2009). The difference in $\mathrm{BP}_{\mathrm{ND}}$ levels are probably caused by differences in methodology (scanner, software, ROIs) and/or subject characteristics between the studies. However, possible methodological differences compared with the earlier studies have no effect on the robust group differences presented here.

These findings have implications for possible cognitive mechanisms and the therapeutic efficacy of mu-opioid antagonists. Abnormalities were observed predominantly in key structures related to reward processing, such as the nucleus accumbens, lateral orbitofrontal cortex, ventrolateral prefrontal cortex, hippocampus, and thalamus with $\left[{ }^{11} \mathrm{C}\right]$ carfentanil (Haber and Knutson, 2010). The findings may reflect either lower mu-opioid receptor density or greater endogenous opioid release. The mu-opioid receptor is implicated in hedonic processing (Berridge et al, 2009) and incentive motivation (Cambridge et al, 2013; Ziauddeen et al, 2013). In humans with moderate binge eating, mu-opioid receptor antagonism appears to decrease motivational responses to salient food cues and enhance subjective hedonic ratings to food cues for which effort or motivation was expended but decrease hedonic ratings to sweetened food consumption (Cambridge et al, 2013; Voon, 2015; Ziauddeen et al, 2013). Thus, low baseline mu-opioid receptor availability may increase pleasure associated with food cues or the expectation of food for which effort is expended but decrease pleasure associated with the act of consumption, thereby leading to out-of-control binge eating behaviors. Two novel compounds targeting the mu-opioid receptor have not shown efficacy in binge eating or weight control (McElroy et al, 2013; ' Ziauddeen et al, 2013). This lack of efficacy of mu-opioid receptor antagonists in BED 
contrasts with their efficacy in substance use disorders and particularly alcohol use disorders (Rosner et al, 2010), an observation that may reflect the differences in baseline receptor availability. Further studies investigating mu-opioid receptor availability as a marker for treatment response is indicated.

We note that midbrain $\left[{ }^{11} \mathrm{C}\right]$ carfentanil binding was decreased in BED patients compared with PG patients and controls, without similar differences in $\left[{ }^{18} \mathrm{~F}\right]$ fluorodopa binding. This suggests that the reduced mu-opioid receptor availability may be an independent finding even in dopamine-rich areas, despite the crosstalk between muopioid receptors and dopamine neurons (Li et al, 2016).

\section{Dopamine Synthesis Capacity}

We further highlight differences in BED and PG as a function of striatal dopamine synthesis capacity with decreased capacity in BED with no differences observed in PG. These findings corroborate observations of mixed findings across substance use disorders. Cocaine use disorders are associated with lower dopamine synthesis capacity (Wu et al, 1997) with no differences observed for alcohol (Kienast et al, 2013) or nicotine use disorders (Bloomfield et al, 2014). The observation of low striatal dopamine synthesis capacity in BED may be particularly relevant to the efficacy of lisdexamfetamine in BED (McElroy et al, 2015), which inhibits dopamine and noradrenergic transporters and enhances synaptic neurotransmitter levels. Our findings may be relevant as potential biomarkers for the therapeutic efficacy for lisdexamfetamine.

We previously reported that PG is not associated with differences in D2 receptor availability relative to controls (Joutsa et al, 2012), which is confirmed by other studies (Boileau et al, 2013; Clark et al, 2012; Linnet et al, 2012). Together with our current study, these observations suggest that there is no marked group-level basal pre- or postsynaptic dopaminergic hypo- or hyperactivity in PG. Although dopamine agonists can induce pathological gambling (Weintraub et al, 2010), dopamine D2 receptor availability and dopamine synthesis capacity are unaltered in PG patients (in contrast with observations in substance addictions). Our findings are consistent with recent theories that subtypes of addictions, namely opiate and psychostimulant use disorders, are behaviorally and neurobiologically distinct (Badiani et al, 2011). These results extend this concept of heterogeneity to behavioral addictions.

\section{Limitations}

Although we note that our sample size of BED subjects was relatively small due to difficulties in recruiting suitable subjects, and thus these results need replication in future studies, we compared this with a large healthy control population (total sample of BED and healthy controls: 24). Furthermore, we emphasize that the effect size for the difference between BED and healthy controls in the nucleus accumbens was large for both neurotransmitter effects (eg, nucleus accumbens $\left[{ }^{11} \mathrm{C}\right]$ carfentanil Cohen's $d: 2.77$, effect size $r=0.81$; $\left[{ }^{18} \mathrm{~F}\right]$ fluorodopa Cohen's $d$ : 2.37 , effect size $r=0.76)$. We also accounted for possible effects that may act as confounders (eg, addiction severity, medication, gender, concurrent smoking, and depression) and suggest that these factors are unlikely to explain our findings. Both PG and BED fulfilled diagnostic criteria with daily urges to gamble or binge eat; notably, BED subjects had a longer duration of disease relative to PG subjects. However, neither symptom severity nor duration correlated with binding. Similar to the gender distribution of BED and PG in the general population (Kessler et al, 2013; Kessler et al, 2008), our sample had more PG males and only females with BED. However, a specific analysis of female subjects did not affect the results. Because smoking is also a potential confounding factor, the results were confirmed in non-smoking subjects only. The depression scores were also comparable between BED and PG, and major depression was an exclusion criterion, which suggested that depression was unlikely to account for these findings. Finally, participants were not using medications known to have effects on opioid or dopamine system.

\section{CONCLUSION}

In summary, we emphasize intrinsic differences in opioid and dopamine function between two subtypes of behavioral addictions. These findings highlight the heterogeneity of subtypes of addictions and may also reflect potential neurobiological substrates, which could lead an individual towards the pathological use of a specific drug or behavior. Our findings also have implications for underlying cognitive and therapeutic mechanisms and could potentially be used as biomarkers for treatment.

\section{FUNDING AND DISCLOSURE}

This study was supported by the Academy of Finland (grant \#256836), the Finnish Medical Foundation, the Finnish Alcohol Research Foundation and the Turku University Central Hospital (EVO grants). VV was supported by a Wellcome Trust Fellowship (093705/10/Z). The authors declare no conflict of interest.

\section{ACKNOWLEDGMENTS}

We thank the personnel of the Turku PET Centre for their expertise and assistance in PET and MRI imaging.

\section{REFERENCES}

Alakurtti K, Johansson JJ, Joutsa J, Laine M, Bäckman L, Nyberg L et al (2015). Long-term test-retest reliability of striatal and extrastriatal dopamine D2/3 receptor binding: study with [(11)C] raclopride and high-resolution PET. J Cereb Blood Flow Metab 35: 1199-1205.

Badiani A, Belin D, Epstein D, Calu D, Shaham Y (2011). Opiate versus psychostimulant addiction: the differences do matter. Nat Rev Neurosci 12: 685-700.

Berridge KC, Robinson TE, Aldridge JW (2009). Dissecting components of reward: 'liking', 'wanting', and learning. Curr Opin Pharmacol 9: 65-73.

Blanco C, Hanania J, Petry NM, Wall MM, Wang S, Jin CJ et al (2015). Towards a comprehensive developmental model of pathological gambling. Addiction 110: 1340-1351. 
Bloomfield MA, Pepper F, Egerton A, Demjaha A, Tomasi G, Mouchlianitis E et al (2014). Dopamine function in cigarette smokers: an [(1)(8)F]-DOPA PET study. Neuropsychopharmacology 39: 2397-2404.

Boileau I, Payer D, Chugani B, Lobo D, Behzadi A, Rusjan PM et al (2013). The D2/3 dopamine receptor in pathological gambling: a positron emission tomography study with [11C]-(+)-propylhexahydro-naphtho-oxazin and [11C]raclopride. Addiction 108: 953-963.

Boileau I, Payer D, Chugani B, Lobo DS, Houle S, Wilson AA et al (2014). In vivo evidence for greater amphetamine-induced dopamine release in pathological gambling: a positron emission tomography study with [(11)C]-(+)-PHNO. Mol Psychiatry 19: 1305-1313.

Brownley KA, Berkman ND, Peat CM, Lohr KN, Cullen KE, Bann CM et al (2016). Binge-eating disorder in adults: a systematic review and meta-analysis. Ann Intern Med 165: 409-420.

Cambridge VC, Ziauddeen H, Nathan PJ, Subramaniam N, Dodds C, Chamberlain SR et al (2013). Neural and behavioral effects of a novel mu opioid receptor antagonist in binge-eating obese people. Biol Psychiatry 73: 887-894.

Clark L, Stokes PR, Wu K, Michalczuk R, Benecke A, Watson BJ et al (2012). Striatal dopamine $\mathrm{D}_{2} / \mathrm{D}_{3}$ receptor binding in pathological gambling is correlated with mood-related impulsivity. Neuroimage 63: 40-46.

de Jong HW, van Velden FH, Kloet RW, Buijs FL, Boellaard R, Lammertsma AA (2007). Performance evaluation of the ECAT HRRT: an LSO-LYSO double layer high resolution, high sensitivity scanner. Phys Med Biol 52: 1505-1526.

Desikan RS, Ségonne F, Fischl B, Quinn BT, Dickerson BC, Blacker D et al (2006). An automated labeling system for subdividing the human cerebral cortex on MRI scans into gyral based regions of interest. Neuroimage 31: 968-980.

Fischl B, Salat DH, Busa E, Albert M, Dieterich M, Haselgrove C et al (2002). Whole brain segmentation: automated labeling of neuroanatomical structures in the human brain. Neuron 33: 341-355.

Forsback S, Eskola O, Bergman J, Haaparanta M, Solin O (2009). Alternative solvents for electrophilic synthesis of 6-[18F]fluoroL-DOPA. J Labelled Combd Rad 52: 286-288.

Giuliano C, Cottone P (2015). The role of the opioid system in binge eating disorder. CNS Spectr 20: 537-545.

Grant JE, Kim SW, Hartman BK (2008). A double-blind, placebocontrolled study of the opiate antagonist naltrexone in the treatment of pathological gambling urges. J Clin Psychiatry 69: 783-789.

Grant JE, Odlaug BL, Potenza MN, Hollander E, Kim SW (2010a). Nalmefene in the treatment of pathological gambling: multicentre, double-blind, placebo-controlled study. $\mathrm{Br} J$ Psychiatry 197: 330-331.

Grant JE, Potenza MN, Hollander E, Cunningham-Williams R, Nurminen T, Smits G et al (2006). Multicenter investigation of the opioid antagonist nalmefene in the treatment of pathological gambling. Am J Psychiatry 163: 303-312.

Grant JE, Potenza MN, Weinstein A, Gorelick DA (2010b). Introduction to behavioral addictions. Am J Drug Alcohol Abuse 36: 233-241.

Gunn RN, Lammertsma AA, Hume SP, Cunningham VJ (1997). Parametric imaging of ligand-receptor binding in PET using a simplified reference region model. Neuroimage 6: 279-287.

Haber SN, Knutson B (2010). The reward circuit: linking primate anatomy and human imaging. Neuropsychopharmacology 35: 4-26.

Heinz A, Reimold M, Wrase J, Hermann D, Croissant B, Mundle G et al (2005). Correlation of stable elevations in striatal mu-opioid receptor availability in detoxified alcoholic patients with alcohol craving: a positron emission tomography study using carbon 11-labeled carfentanil. Arch General Psychiatry 62: 57-64.
Hirvonen J, Aalto S, Hagelberg N, Maksimow A, Ingman K, Oikonen V et al (2009). Measurement of central mu-opioid receptor binding in vivo with PET and [11C]carfentanil: a testretest study in healthy subjects. Eur J Nucl Med Mol Imaging 36: 275-286.

Joutsa J, Johansson J, Niemelä S, Ollikainen A, Hirvonen MM, Piepponen $\mathrm{P}$ et al (2012). Mesolimbic dopamine release is linked to symptom severity in pathological gambling. Neuroimage 60: 1992-1999.

Karlsson HK, Tuulari JJ, Tuominen L, Hirvonen J, Honka H, Parkkola $\mathrm{R}$ et al (2015). Weight loss after bariatric surgery normalizes brain opioid receptors in morbid obesity. $\mathrm{Mol}$ Psychiatry 21: 1057-1062.

Keller SH, Sibomana M, Olesen OV, Svarer C, Holm S, Andersen FL et al (2012). Methods for motion correction evaluation using 18F-FDG human brain scans on a high-resolution PET scanner. J Nucl Med 53: 495-504.

Kessler RC, Berglund PA, Chiu WT, Deitz AC, Hudson JI, Shahly V et al (2013). The prevalence and correlates of binge eating disorder in the World Health Organization World Mental Health Surveys. Biol Psychiatry 73: 904-914.

Kessler RC, Hwang I, LaBrie R, Petukhova M, Sampson NA, Winters KC et al (2008). DSM-IV pathological gambling in the National Comorbidity Survey Replication. Psychol Med 38: 1351-1360.

Kienast T, Schlagenhauf F, Rapp MA, Wrase J, Daig I, Buchholz HG et al (2013). Dopamine-modulated aversive emotion processing fails in alcohol-dependent patients. Pharmacopsychiatry 46: 130-136.

Kim SW, Grant JE, Adson DE, Shin YC (2001). Double-blind naltrexone and placebo comparison study in the treatment of pathological gambling. Biol Psychiatry 49: 914-921.

Kovanen L, Basnet S, Castrén S, Pankakoski M, Saarikoski ST, Partonen $\mathrm{T}$ et al (2016). A randomised, double-blind, placebocontrolled trial of as-needed naltrexone in the treatment of pathological gambling. Eur Addict Res 22: 70-79.

Li C, Sugam JA, Lowery-Gionta EG, McElligott ZA, McCall NM, Lopez AJ et al (2016). Mu opioid receptor modulation of dopamine neurons in the periaqueductal gray/dorsal raphe: a role in regulation of pain. Neuropsychopharmacology 41: 2122-2132.

Li Y, van den Pol AN (2008). Mu-opioid receptor-mediated depression of the hypothalamic hypocretin/orexin arousal system. J Neurosci 28: 2814-2819.

Linnet J, Mouridsen K, Peterson E, Møller A, Doudet DJ, Gjedde A (2012). Striatal dopamine release codes uncertainty in pathological gambling. Psychiatry Res 204: 55-60.

McElroy SL, Guerdjikova AI, Blom TJ, Crow SJ, Memisoglu A, Silverman BL et al (2013). A placebo-controlled pilot study of the novel opioid receptor antagonist ALKS-33 in binge eating disorder. Int J Eating Disord 46: 239-245.

McElroy SL, Hudson JI, Mitchell JE, Wilfley D, Ferreira-Cornwell MC, Gao J et al (2015). Efficacy and safety of lisdexamfetamine for treatment of adults with moderate to severe binge-eating disorder: a randomized clinical trial. JAMA Psychiatry 72: 235-246.

Mick I, Myers J, Ramos AC, Stokes PR, Erritzoe D, Colasanti A et al (2015). Blunted endogenous opioid release following an oral amphetamine challenge in pathological gamblers. Neuropsychopharmacology 41: 1742-1750.

Patlak CS, Blasberg RG (1985). Graphical evaluation of blood-tobrain transfer constants from multiple-time uptake data. J Cereb Blood Flow Metab 5: 584-590.

Potenza MN, Xian H, Shah K, Scherrer JF, Eisen SA (2005). Shared genetic contributions to pathological gambling and major depression in men. Arch Gen Psychiatry 62: 1015-1021.

Robbins TW, Clark L (2015). Behavioral addictions. Curr Opin Neurobiol 30: 66-72. 
Rosner S, Hackl-Herrwerth A, Leucht S, Vecchi S, Srisurapanont M, Soyka M (2010). Opioid antagonists for alcohol dependence. Cochrane Database Syst Rev CD001867.

Toneatto T, Brands B, Selby P (2009). A randomized, double-blind, placebo-controlled trial of naltrexone in the treatment of concurrent alcohol use disorder and pathological gambling. Am J Addict 18: 219-225.

Volkow ND, Tomasi D, Wang GJ, Logan J, Alexoff DL, Jayne M et al (2014). Stimulant-induced dopamine increases are markedly blunted in active cocaine abusers. Mol Psychiatry 19: 1037-1043. Voon V (2015). Cognitive biases in binge eating disorder: the hijacking of decision making. CNS Spectr 20: 566-573.

Wang GJ, Geliebter A, Volkow ND, Telang FW, Logan J, Jayne MC et al (2011). Enhanced striatal dopamine release during food stimulation in binge eating disorder. Obesity 19: 1601-1608.

Weintraub D, Koester J, Potenza MN, Siderowf AD, Stacy M, Voon V et al (2010). Impulse control disorders in Parkinson disease: a cross-sectional study of 3090 patients. Arch Neurol 67: 589-595.
Woods RP, Grafton ST, Holmes CJ, Cherry SR, Mazziotta JC (1998). Automated image registration: I. General methods and intrasubject, intramodality validation. J Comput Assist Tomogr 22: 139-152.

Wu JC, Bell K, Najafi A, Widmark C, Keator D, Tang C et al (1997). Decreasing striatal 6-FDOPA uptake with increasing duration of cocaine withdrawal. Neuropsychopharmacology 17: 402-409.

Yau YH, Potenza MN (2015). Gambling disorder and other behavioral addictions: recognition and treatment. Harv Rev Psychiatry 23: 134-146.

Ziauddeen H, Chamberlain SR, Nathan PJ, Koch A, Maltby K, Bush $\mathrm{M}$ et al (2013). Effects of the mu-opioid receptor antagonist GSK1521498 on hedonic and consummatory eating behaviour: a proof of mechanism study in binge-eating obese subjects. Mol Psychiatry 18: 1287-1293.

Zubieta JK, Gorelick DA, Stauffer R, Ravert HT, Dannals RF, Frost JJ (1996). Increased mu opioid receptor binding detected by PET in cocaine-dependent men is associated with cocaine craving. NatMed 2: 1225-1229.

Supplementary Information accompanies the paper on the Neuropsychopharmacology website (http://www.nature.com/npp) 